\title{
REPORTS ON
}

\section{Hospitals of the United Kingdom.}

\author{
By SIR HENRY BURDETT, K.C.B., K.C.V.O.
}

\section{SERIES III.}

\section{KENT COUNTY OPHTHALMIC HOSPITAL, MAIDSTONE.}

THIs hospital was instituted in 1847, and provides treatment for patients suffering from diseases of the eye, ear, nose, and throat. It contains thirty-nine beds.

On entering, one is faced by an imposing staircase, which leads to the women's wards, those for the men being situated on the ground floor. The chief features of the hospital are two very large and attractiive double-windowed day rooms, one for men and one for women, and an addition to the out-patients' department which provides accommodation for the treatment of an unusually large number of adenoid cases, of which this hospital seems to have the monopoly so far as Maidstone and the district are concerned. It is manifest to us that as the majority of adenoid cases appear to be sent to this type of hospital by the County Education Authorities, the authorities here and everywhere where this practice prevails should agree to defray the cost of treating these cases and also to pay the cost of the medical service.

The most has been made of the garden, of which the atiractiveness has been increased by the addition of a walk extending its whole length, and over this walk have been trained a nurnber of crimson and other ramblers, which have a most pleasing effect during the time the roses are in bloom.

The Matron, Miss Gertrude Brown, has been connected with this hospital for a number of years, and her services and skilled co-operation are specially acknowledged by the honorary surgeons in their report to the hospital. We note with satisfaction that the enlargement of the outpatients' department was accompanied by the appointment of an cut-patient sister to take charge of the work. Included in the additions are a consulting-room, dark-room, the sight-testing range for eye patients, and a casualty operation theatre. The total cost was some $£ 1,000$.

This hospital contains a chapel, which is an unusual addition to a special hospital of its type.

The financial position of the hospital would appear from the accounts to be reasonably saticfactory. That a revenue of $£ 1,025$ a year should be derived from investments, out of a total income of $£ 2,120$, is a notable fact due, we believe, to the circumstance that this hospital has been established upwards of sixty years. Again, it is surprising that no payments appear to have been made by the patients, an omission which, having regard to the nature and character of the work done, demands the attention of the committee. The hospital has, then, in this omission to take payments from its patients, a large reserve of income available, for it may clearly follow the example of other special hospitals by making a charge for both outpatients' and in-patients' treatment under proper regulations which exhibit a due regard to the circumstances of each patient.

\section{The Prevention of Typhoid Fever.}

THE success of the inoculation method of preventing typhoid fever in the British Army is not a matter of doubt in the minds of those who have had opportunities for observing it or of examining the official statistics. Nevertheless, Sir William Leishman has done good service by reprinting in the Journal of the Royal Army Medical Corps the figures of typhoid fever incidence during recent years. Sir William's argument can be briefly summarised. The returns for many years show that the usual number of typhoid-fever cases in the British garrison in India was anywhere from 1,200 to 1,600 annually. In exceptional years these figures were departed from: thus in 1897 an? 1898 the frontier compaigns took the figure up into the two thousands; and in 1900 and 1901 the departure of many troops for Africa and the cessation of influx of young recruits brought the figures down to 970 and 776 respectively. By 1902 they had risen again to 1,012 . in 1903 to 1,366 , and in 1904 to 1,384. In 1905 inoculation was reintroduced as a voluntary matter, but it was not until 1909 that it became sufficiently general to exercise a preponderating influence. The figures tell their own tale: In 1905 there were 1,146 cases; in 1906 there were 1,095 ; in 1907,910 ; in 1908 , 998 ; in 1909,616 ; in 1910,296 ; in 1911, 170 ; and in 1912,118 . The case mortality has also declined, though at a less striking rate; at the present time typhoid fever is about one-third as fatal to the inoculated as to the non-inoculated, and the former run about one-fourth the risk of catching it than the latter do. Sir William Leishman argues that it should be no longer left to the individual soldier whether or no he wishes to be inoculated. He admits improvements in sanitation and in diagnosis, but emphasises his conviction that progress is mainly due to the extended employment of anti-typhoid vaccine. 